\title{
ESTUDIO CRÍTICO DE UN NUEVO DILEMA EN EL SISTEMA JURÍDICO MEXICANO. LA REGULACIÓN DEL ABORTO INDUCIDO: ¿DERECHO DEL NASCITURUS A NACER O DERECHO DE LA MUJER A LA LIBRE DETERMINACIÓN SOBRE SU PROPIO CUERPO?
}

CRITICAL STUDY OF A NEW DILEMMA IN THE MEXICAN LEGAL SYSTEM. THE REGULATION OF INDUCED ABORTION: A

RIGHT OF THE UNBORN CHILD TO BE BORN OR WOMAN'S RIGHT TO SELF-DETERMINATION OVER THEIR OWN BODIES?

\section{LUIS IGNACIO NAVARRo GONZÁLEZ}

Profesor de la División de Estudios Jurídicos de la Universidad de Guadalajara (México)

Palabras clave: Nasciturus, derecho a la vida, interrupción voluntaria del embarazo, derecho a la autodeterminación, teoría crítica del derecho.

Keywords: Nasciturus, right to life, voluntary termination of pregnancy, self-determination, critical theory of law.

Resumen: Los complejos problemas del aborto inducido se han convertido en uno de los temas nacionales de muchos países, incluido México.

Los tres ejes metodológicos fundamentales sobre los que se asienta el presente trabajo son: La defensa de la teoría crítica de los derechos humanos, la interdisciplinariedad y el método de la interpretación jurídica sistemática. 


\section{LuIS IgNACIO NAVARRo GONZÁLEZ}

La reforma del Código penal para el Distrito Federal, de 2007, ha supuesto la aparición de un nuevo dilema, que tiene cinco niveles de concreción: el dilema semántico, el dilema lógico, el dilema epistemológico, el dilema moral y, finalmente, el dilema legal.

El dilema legal está determinado por dos factores: la materia regulada y la politica legislativa seguida en la reforma del Código penal del Distrito Federal; más exactamente, en el ámbito competencial, como consecuencia de que no están adecuadamente delineadas las competencias legislativas -con relación al aborto inducido-entre la esfera federal y la estatal. La reforma legal da origen a una duplicidad de leyes en ambas esferas jurídicas, que regulan idénticas conductas pero con soluciones antagónicas.

Abstract: The complex problems of induced abortion have become one of the national issues in many countries, including Mexico.

The three fundamental methodological foundations on which this work is based are the defense of critical theory of human rights, interdisciplinary and systematic method of legal interpretation.

The reform of penal code for the Federal District, 2007, has implied to the emergence of a new dilemma, which has five levels of concretion: semantic, logical, epistemological, and finally, legal dilemma.

The legal dilemma is determined by two factors: the legal content andlegislative policy in the reform of the Penal Code of the Federal District. They are not properly found the legislative competence in relative to abortion between the Federal and the State level. That produces laws duplication about identical behaviors, but with antagonistic solutions.

Recepción original: 13/12/2015

Aceptación original:30/02/2015

Sumario: I. Introducción. II. Objetivos. III. Metodología. III.1. La Teoría Crítica del Derecho. III.2. Metodología interdisciplinaria. III.3. Presupuestos éticos. III.3.A. Ética de la alteridad. III.3.B. Ética de la compasión. III.3.C Ética de la liberación. III.3.D. Ética construida desde las víctimas. III.3.E. La ética personalista. III.3.F. La ética comunicativa. III.4. La Teoría de los Derechos Humanos. III.5. Metodología de interpretación de las normas jurídicas con relación al aborto inducido: la interpretación sistemática. III.5.A. La interpretación contextual. III.5.B. La interpretación integradora. III.5.C. La interpretación realizada conforme a los valores jurídicos fundamentales. III.5.D. La interpretación realizada conforme a la Cláusula General Antidiscriminatoria. III.5.E. La interpretación de la Constitución y 
desde la Constitución. III.5.F. La interpretación conforme al principio de legalidad constitucional. III.5.G. La interpretación conforme al principio de unidad constitucional. III.5.H. La interpretación conforme al principio de supremacía constitucional. III.5.I. La interpretación realizada conforme al principio de no contradicción. III.5.J. La interpretación realizada conforme al principio de prohibición de interpretación restrictiva. III.5.K. Interpretación realizada conforme al reconocimiento y garantía del principio favor libertatis. III.5.L. Interpretación realizada en el sentido de reconocer y garantizar el principio in dubio pro libértate. IV. El carácter dilemático del aborto inducido en el ámbito del Derecho mexicano. IV.1. El concepto de dilema. IV.2. Los cinco tipos de dilemas en la legislación mexicana referente al aborto inducido. IV.2.A. El dilema semántico. IV.2.B. El dilema lógico. IV.2.C. El dilema epistemológico. IV.2.D. El dilema moral. IV.2.E. El dilema legal. IV.2.E: a. Contradicción con los valores jurídicos fundamentales. IV.2.E: b. Contradicción con los principios jurídicos fundamentales. IV.2.E: c. Contradicción con relación a los derechos fundamentales. V. Conclusiones. VI. Propuestas. VII. Bibliografía.

\section{INTRODUCCIÓN}

El aborto inducido, que hasta ahora recibía otras denominaciones, tales como aborto voluntario, aborto procurado y aborto provocado ha recibido desde hace pocos años una nueva denominación: interrupción voluntaria del embarazo que ha venido a desvirtuar su significado originario.

Puede ser definido como aquella práctica consistente en provocar la finalización prematura del embarazo, impidiendo el desarrollo vital del embrión o feto, para conseguir su eliminación.

Se trata de un hecho social denso y complejo que ocurre en el contexto de diversos tipos de relaciones de poder: de género, económicas, jurídico-legales.

Su complejidad deriva no del hecho de se trate de un mero sumatorio de planos y relaciones sino porque ocurre en la interacción y articulación de esos diferentes planos y sistemas de relaciones. ${ }^{1}$ Tal es su complejidad que las preguntas fundamentales que suscita son cuestiones abiertas. Por eso se puede afirmar que no tienen respuestas que sean universalmente válidas e incontestables. Así sucede tam-

\footnotetext{
${ }^{1}$ ROSTAGNOL, Susana: Lugares y sentidos del aborto voluntario: un diálogo con la bioética en Perspectivas bioéticas, Ediciones del Signo, Año 2011, N. 21, p. 46.
} 


\section{LuIS IgNACIO NAVARRo GONZÁLEZ}

bién en el ámbito estrictamente jurídico y un buen ejemplo lo encontramos en la actual legislación mexicana.

Es, además, una realidad, dramática, que afecta hoy -pero también en el pasado- a todas las sociedades y que por su propia naturaleza el Derecho no puede ni debe inhibirse ${ }^{2}$.

Su tratamiento jurídico se ubica en la intersección sensible de múltiples discrepancias científicas dentro de diversas áreas de conocimiento tanto del Derecho como de otras áreas de conocimiento.

En el ámbito del derecho afecta a la ciencia jurídica (Derecho Constitucional, Derecho Penal, Derecho Internacional...), a las Ciencias sobre el Derecho (la Psicología jurídica, la Historia del Derecho, la Sociología jurídica, la Antropología Jurídica) a la Filosofía del Derecho, a la Teoría del Derecho y al Derecho Comparado ${ }^{3}$. También afecta a su tratamiento jurídico el conocimiento de otras áreas de conocimiento, como son las ciencias de la salud, la Ética Pública, la moral critica, la Bioética, la Antropología, la Sociología, la Filosofía Política, la Teoría de los Derechos Humanos, la Demografía, la Filosofía del Lenguaje, especialmente de la Semántica... Además, está afectado por fuertes y vehementes planteamientos ideológicos y por sentimientos y creencias religiosas de muy diferente signo.

Esa es la razón que explica que su tratamiento normativo y que cualquier decisión al respecto emanada de cualquiera de los tres Poderes del Estado adquiera una inmediata proyección política y, lo que es aún más significativo, genere una viva polémica social, alcanzando de inmediato una gran proyección mediática. ${ }^{4}$

En el ámbito del Derecho Penal el aborto inducido es una de las cuestiones más debatidas; lo cual se explica por cuatro razones fundamentales:

${ }^{2}$ Opinión del Comité de Bioética de España a propósito del Proyecto de Ley Orgánica de Salud Sexual y Reproductiva y de la Interrupción voluntaria del embarazo, 7 de Octubre de 2009, p. 4 en Internet: http://www.comitedebioetica.es/documentacion/docs/ es/consenso_interrupcion_embarazo_comite_bioetica_oct_2009.pdf.

${ }^{3}$ CARPIZ̄O, Jorge, VALADÉS, Diego: Derechos Humanos. Aborto y eutanasia. UNAM, Instituto de Investigaciones Jurídicas, México, 2008, p. 7.

${ }^{4}$ Consejo Fiscal: Informe aprobado por el Consejo Fiscal sobre el Anteproyecto de Ley de Salud Sexual y reproductiva y de la interrupción voluntaria del embarazo en Internet: http://www.abortoinformacionmedica.es/2009/06/28/informe-del-consejo-fiscal-sobre-el-anteproyecto/

El anteproyecto se aprobó, finalmente, como Ley Orgánica 2/2010, de 3 de marzo, de salud sexual y reproductiva y de la interrupción voluntaria del embarazo, publicada en el BOE el jueves 4 de Marzo de 2010. 
1. Su punición choca frontalmente con las posiciones proabortistas, que defienden la atipicidad y la admisibilidad de las conductas que lo producen.

2. Se afirma que su punibilidad implica una grave contradicción porque pese a su relevancia social y el elevado número de abortos producidos, el número de asuntos de esta naturaleza que llegan a los tribunales es muy reducido.

3. ${ }^{\circ}$ La represión penal y la función de prevención general de las penas impuestas resultan sumamente ineficaces, porque no han evitado que se siguieran practicando a lo largo de los años.

4. ${ }^{\circ}$ La represión penal ha podido convertir el aborto inducido, en determinados casos, en un instrumento de alto riesgo para la vida y la salud de las mujeres que -para ocultar la acción delictiva- se ven en la necesidad de realizar las prácticas abortivas en pésimas condiciones sanitarias y con personas incompetentes en el ámbito de la medicina. Esta situación genera una discriminación entre las propias mujeres, ya que la posibilidad de acceder a un aborto seguro es muy diferente en función de la capacidad económica y cultural de las mismas. ${ }^{5}$

Contemplado en la perspectiva histórica podemos afirmar sin tener miedo a hacer incurrir en una afirmación exagerada, que el aborto, especialmente el aborto inducido, es un problema secular en la Historia de la Humanidad ${ }^{6}$.

La compleja problemática del aborto inducido tiene tal relevancia social, que se puede afirmar que se ha convertido en uno de los temas nacionales de muchos países, tales como: Alemania, Francia, Italia, España o México. Se ha llegado a afirmar, incluso, que se trata de una cuestión nodal para todos y cada uno de los habitantes de México.

\section{OBJETIVOS}

El objetivo principal del presente trabajo consiste en estudiar, aunque sea brevemente, por razón del espacio disponible, a partir de una definición de dilema, si la actual regulación mexicana del aborto inducido en el Código Penal del Distrito Federal ha producido el surgimiento de un nuevo dilema legal, como consecuencia de la promulga-

${ }^{5}$ Opinión del Comité de Bioética... Op. Cit, p. 5 en Internet: http://www.comitedebioetica.es/documentacion/docs/es/consenso_interrupcion_embarazo_comite_bioetica_oct_2009.pdf.

${ }^{6}$ BERMÚDEZ VALDIVIA, Violeta: La regulación jurídica del aborto en América Latina y el Caribe, CLADEM, Lima, 1998, p. 13. 


\section{LuIS IgNACIO NAVARRo GONZÁLEZ}

ción del Decreto por el que se reforma el Código Penal para el Distrito Federal y se Adiciona la Ley de Salud para el Distrito Federal ${ }^{7}$. Por virtud del cual se modificaron los artículos 144, 145, 146 y 147 del Código Penal para el Distrito Federal (artículo 1 del Decreto), se adiciono un tercer párrafo al artículo 16 Bis 6, y el artículo 16 Bis 8 a la Ley de Salud del Distrito Federal (Artículo 2 del Decreto)

Es incuestionable que en el aborto se dan cita una serie de dilemas de naturaleza moral. ${ }^{8}$ Pero, ¿Ocurre lo mismo en el ámbito jurídico? Y en el supuesto de que la respuesta sea afirmativa, será preciso analizar los diversos niveles de su concreción. Especialmente interesante, por sus consecuencias sociales, será verificar la existencia de dilemas en el máximo nivel jurídico, esto es, en el rango constitucional.

Esta propuesta de planteamientos suscita, a su vez, una serie de preguntas que son determinantes para poder afirmar si, efectivamente, estamos ante un dilema jurídico de indudable relevancia. Esas preguntas se pueden sintetizar al menos en dos fundamentales:

1. ¿Cuál es la causa de que se forme un nuevo dilema jurídico?

$2 .^{a}$ ¿El dilema se da sólo en el estricto ámbito jurídico-normativo del aborto inducido o, por el contrario, hunde sus raíces en otros ámbitos que lo preconstituyen?

\section{METODOLOGÍA}

Para tratar de dar respuesta a las diversas cuestiones que hemos planteado en el apartado anterior, se ha hecho preciso estructurar los contenidos axiológicos, fácticos, doctrinales, ideológicos, normativos y jurisprudenciales; siguiendo una serie de parámetros metodológicos, que se describen a continuación, y que permiten plantear los problemas fundamentales concernientes al aborto inducido y a su actual regulación en el sistema jurídico mexicano y, más específicamente, en el subsistema del Distrito Federal.

Los tres ejes metodológicos fundamentales sobre los que se asienta el presente trabajo son: la defensa de la teoría crítica de los derechos

${ }^{7}$ Gaceta Oficial del Distrito Federal, N. ${ }^{\circ}$ 70, México, Distrito Federal, 26 de Abril de 2007, pp. 2 y ss.

${ }^{8}$ Vid., por ejemplo, entre la abundantísima bibliografía, MASIÁ CLAVEL, Juan: Bioética y Antropología, 2. ${ }^{a}$ Edición, Universidad Pontificia de Comillas, Madrid, 1998. CAMPOS SALAS, Jeanette: El dilema del aborto, Uruk Editores, 2008. GARCÍA PASCUAL, C: Cuestiones de vida o muerte: los dilemas éticos del aborto en Derechos y Libertades, N. ${ }^{\circ} 16$, Época II, Enero de 2007, pp. 181 y ss. 
ESTUDIO CRÍTICO DE UN NUEVO DILEMA EN EL SISTEMA JURÍDICO MEXICANO...

humanos, de la interdisciplinariedad y del método de la interpretación jurídica sistemática.

\section{III.1. La Teoría Critica de los Derechos Humanos}

Por Teoría Critica de los Derechos Humanos entiendo aquel conjunto de argumentaciones que -a partir de la síntesis dialógica de las principales líneas seguidas por varias de las Teorías Críticas del Derecho existentes ${ }^{9}$ - busca explicar y potenciar el papel del Derecho y de los defensores de los derechos humanos en el reconocimiento y garantía de todos los seres humanos en cuanto que titulares de un poder social. ${ }^{10}$

Los principales argumentos que asumimos como adecuados para examinar críticamente el aborto inducido en el actual sistema jurídico mexicano son los siguientes:

a) Debe superarse la teoría tradicional del Derecho como consecuencia de los profundos cambios sociales existentes en todo el mundo a partir de la aparición y desarrollo de los procesos globalizadores que han contribuido a erosionar, de forma decisiva, sus presupuestos metodológicos y doctrinales.

b) Debe ir más allá de la idea del papel exclusivo del Estado como agente jurídico fundamental. Frente a ella se exige ahora tomar en consideración los nuevos actores del Derecho, como son las organizaciones no gubernamentales y los distintos movimientos sociales.

c) La antigua descripción geométrica del Derecho como pirámide normativa, queda superada por la descripción reticular del Derecho, que se corresponde a la estructura de la sociedad global: la sociedad red. Los viejos conceptos de regulación y sanción son completados

${ }^{9}$ WOLKNER, Antonio Carlos: Introducción al pensamiento jurídico crítico, $1 .^{\text {a }}$ Edición, ILSA, Bogotá, 2003, pp. 45 y ss. COELHO, Luiz Fernando: Teoría Crítica del Derecho, 4. ${ }^{a}$ Edición, Juruá, Curitiba, 2012. SÁNCHEZ RUBIO, David, HERRERA FLORES, Joaquín, DE CARVALHO, Salo: Direitos Humanos e Globalização. Fundamentos e Posibilidadades desde a Teoría Critica, 2. ${ }^{\text {a }}$ edición en Homenaje a Joaquín Herrera Flores, Porto Alegre, Edipucrs, 2010. OST, François: Jalons pour une Théorie critique du Droit, Publications des Facultes, Universitaires, St. Louis, Bruselas, 2002.

${ }^{10}$ LIMA TORRADO, Jesús: La teoría del poder como presupuesto de la teoría de los derechos humanos en Revista de la Facultad de Derecho de la Universidad Complutense de Madrid, N. ${ }^{\circ}$ 80, Madrid, 1993, pp. 201 y ss. También en LIMA TORRADO, Jesús, ROVETTA KLYVER, Fernando (Coordinadores): Curso sistemático de Derechos Humanos. Disponible en Internet: http://www.iepala.es/curso_ddhh/ddhh_c.htm 


\section{Luis IgNaCio NaVARRo GoNZÁLEZ}

ahora con los conceptos, entre otros, de comunicación, cooperación y coordinación.

d) Se plantea, como actitud superada, la formulación de una teoría pretendidamente objetivista, meramente descriptora de la realidad. Alternativamente, se formula como necesaria, la búsqueda de una nueva realidad más racional y humana, una realidad que corresponda a la estructura y objetivos del sistema de derechos humanos.

e) Se toma como referencia el sistema de derechos humanos porque «los derechos humanos son el parámetro y la estructura por medio de la cual se articulan los marcos jurídicos que permiten el desarrollo de las personas y la sociedad». ${ }^{11}$ Además los derechos humanos son el núcleo esencial del Estado de Derecho, como es el Estado mexicano. El Capítulo I del Título Primero de la Constitución mexicana tiene como rótulo: «De los Derechos Humanos y sus Garantías», y el párrafo $1 .^{\circ}$ del artículo $1 .^{\circ}$ se establece que: «En los Estados Unidos Mexicanos todas las personas gozarán de los derechos humanos reconocidos en esta Constitución y en los tratados internacionales de los que el Estado Mexicano sea parte, así como de las garantías para su protección, cuyo ejercicio no podrá restringirse ni suspenderse, salvo en los casos y bajo las condiciones que esta Constitución establece» ${ }^{12}$. Por eso el mismo artículo 1. ${ }^{\circ}$ establece que «el Estado deberá prevenir, investigar, sancionar y reparar las violaciones a los derechos humanos, en los términos que establezca la ley».

f) La "pureza metodológica» del positivismo normativista kelseniano queda superada por la defensa de los valores y de los principios jurídicos como instrumento metodológico fundamental.

g) Toda teoría crítica debe denunciar, como se pretende ahora en este trabajo, las diversas formas concretas de irracionalidad con que se expresan en ocasiones los diversos sistemas jurídicos; en este caso, el sistema jurídico mexicano. Esa irracionalidad y los dilemas surgen como consecuencia de las radicales contradicciones en que incurre.

h) Tras la denuncia de las formas concretas de irracionalidad jurídica y política, en sus diversas manifestaciones normativas e institucionales, se impone proponer alternativas que respondan a formas de racionalidad superior.

${ }^{11}$ DELGADO BALLESTEROS, Gabriela: Aborto en CASTAÑEDA SALGADO, Marta Patricia: La interrupción voluntaria del embarazo: reflexiones teóricas, filosóficas y políticas, Centro de Investigaciones Interdisciplinarias, UNAM, Plaza y Valdés, México, DF, 1. a Edición, 2003, p. 153.

${ }^{12}$ Constitución de los Estados Unidos mexicanos. Disponible en Internet: http:// www.ordenjuridico.gob.mx/Constitucion/cn16.pdf. 
i) Frente a la tradición formalista, que es seguida por muchos autores y que pretende hacer sólo una «fotografía normativa», la Teoría crítica pretende analizar la interacción de los factores sociales y las normas jurídicas: los factores determinantes de la creación y contenidos de las normas y los efectos sociales de la aplicación de las mismas.

j) Se debe partir de una realidad jurídica concreta. En lugar de hacer un análisis ideal y descontextualizado del aborto, se impone el estudio del mismo en un ámbito estrictamente contextualizado, que no es otro que el actual sistema jurídico penal del Distrito Federal.

k) Puesto que las relaciones sociales en las que se inscribe el tema objeto de estudio, esto es el aborto inducido, tienen naturaleza dialéctica, se impone también que las categorías, al no estar aisladas del contexto social en que se producen, tengan también naturaleza dialéctica. ${ }^{13}$

1) Las categorías del pensamiento crítico interpretan la realidad formando parte de esa misma realidad, interactuando con ellas como categorías transformadoras. ${ }^{14}$

\section{III.2. Metodología interdisciplinaria}

Frente a la aún frecuente tesis de defensa de una posición metodológica monista, se ha optado por la adopción de un método interdisciplinario. Se parte de la idea de que el objeto a estudiar no debe -ni puede- ajustarse al método utilizado y preconfigurado por el sujeto cognoscente y sí al revés. Es el método el que debe ajustarse al objeto que se pretende analizar. «Lo cual tiene plena justificación si se tiene en cuenta el carácter multidisciplinar de los derechos humanos», ${ }^{15} \mathrm{y}$ más específicamente, los problemas concernientes al aborto inducido, que constituye el objeto a estudiar: En él se dan cita, como ya se ha indicado problemas de naturaleza antropológica, biológica, científicomedica, sociológica, histórica, jurídica, iusfilosófica, ética, política, demográfica, ideológica y religiosa.

La defensa de una teoría crítica de los derechos humanos implica, en consecuencia, el compromiso de adhesión a lo real, de descu-

${ }^{13}$ COELHO, Luiz Fernando: Teoría crítica del Derecho, Juruá, 4. ${ }^{a}$ Edición, Curitiba, 2012, p. 51.

${ }^{14}$ Ibidem, p. 50.

${ }^{15}$ LIMA TORRADO, J, ROVETTA KLYVER, F.: Curso sistemático de Derechos Humanos. Disponible en Internet: http://www.iepala.es/curso_ddhh/. 


\section{Luis IgNaCio NaVARRo GoNZÁLEZ}

brimiento de la verdad mediante el rechazo a negar, a distorsionar o a omitir la realidad. ${ }^{16}$

Por lo tanto, partimos de un planteamiento interdisciplinario. Por interdisciplinariedad entiendo aquel conjunto de disciplinas conexas entre sí y con relaciones definidas, a fin de que sus actividades no se produzcan en forma aislada, dispersa y fraccionada. ${ }^{17}$

Se privilegia así la integración de diferentes teorías, datos e instrumentos para llegar a un conocimiento multidimensional del objeto de estudio.

El espacio o ámbito de interdisciplinariedad, esto es, el campo interdisciplinario, es el campo de estudio en el que se cruzan las diversas disciplinas científicas y las diversas escuelas y metodologías. En nuestro caso, el campo interdisciplinario está constituido por los problemas fundamentales que plantea el aborto inducido en el actual sistema jurídico mexicano.

Se han desarrollado de este modo, desde un criterio unificador y sistemático, una metodología interdisciplinaria que busca la integración de diversos métodos que actúan de forma necesariamente complementaria. No se trata de una simple componenda, o unión forzada, de líneas de investigación incompatibles. Muy por el contrario, el enfoque metodológico multidisciplinar va dirigido a encontrar una síntesis armónica de los mismos.

Ese enfoque multidisciplinar e interdisciplinar se proyecta de forma coherente, en todas y cada una de las líneas de investigación seguidas.

\subsection{Presupuestos éticos}

La investigación aquí desarrollada está basada en una serie de presupuestos éticos que pueden sintetizarse en los siguientes criterios: ${ }^{18}$

${ }^{16}$ COELHO, Luiz Fernando: Teoría crítica del Derecho, Op. Cit., p.53.

${ }^{17}$ TAMAYO Y TAMAYO, Mario: Diccionario de la investigación científica, 2. ${ }^{a}$ edición, Limusa, México, 2004, p. 172.

${ }^{18}$ En este punto coincido, en líneas generales, con los planteamientos metodológicos defendidos por Olga Lucía LÓPEZ ORTEGA (Comunidades indígenas y derechos humanos en Colombia, Tesis Doctoral, UNED, 2010. No obstante, la referida investigadora, como indica el rótulo de su trabajo, los refiere a los derechos de los pueblos indígenas, mientras que yo los considero con relación al aborto inducido. 


\section{III.3.A. Ética de la alteridad.}

Se propone una defensa de la Ética de la Alteridad, representada por E. Levinas, se parte del papel del otro, del prójimo en la fundamentación ética. Las posiciones doctrinales proabortistas, al estar centradas exclusivamente en la mujer, olvidan -o tratan de eliminar en algunos casos- la dimensión de otredad del nasciturus. Para las posiciones antiabortistas, como es la que aquí defiendo, la otredad está centrada, precisamente, en el nasciturus, aunque también en su relación con la mujer como sujeto de derecho. En virtud esa ética «el otro me interpela, pone en cuestión mi espontaneidad y autosuficiencia y me llama a la responsabilidad». ${ }^{19}$.

\section{III.3.B. Ética de la compasión.}

La ética de la compasión tiene dos vertientes o líneas de interpretación:

La primera línea de interpretación consiste en afirmar que es una ética que trata de encontrar el sentimiento común que subyace en todos los seres vivientes y en todo código ético. Es una ética capaz de generar un espacio de encuentro y comunicación, un reconocimiento de la unidad subyacente a los distintos sistemas éticos. De esa forma se puede conseguir, en conjunción con otras líneas de éticas, superar el egocentrismo y alcanzar una ética universal. ${ }^{20}$ El Manifiesto 2000 para una cultura de Paz y no violencia, de la Unesco, es una buena expresión de la ética de la compasión. ${ }^{21}$ En el presente estudio no me limitaré a analizar, en paralelo, las dos posiciones antagónicas. Intentaré buscar argumentos que permitan puntos doctrinales de encuentro; esto es, planteamientos que intenten conciliar, hasta donde es posible, los argumentos que forman parte del dilema. Con ello se pretende armonizar, en la medida de lo posible, los derechos fundamentales que están en juego: los derechos de la mujer y los derechos del nasciturus.

La segunda interpretación está inspirada en Horkheimer y Benjamín, que afirman que: «el futuro sólo se construye desde el pasado de

${ }^{19}$ DE LA TORRE DÍAZ, Francisco Javier:. ¿Qué metaéticas fundamentan o podrían fundamentar los derechos humanos? en MILANS DE BOSCH PORTOLÉS, Ivan, MADRAZO RIVAS, Enrique, DE LA TORRE DÍAZ, Francisco Javier (Coordinadores): La universidad como agente de cooperación al desarrollo, Dykinson, Madrid, 2002, p. 143 y 144.

${ }^{20}$ VILLALBA, Dokushô: La ética, corazón de una nueva civilización en Conciencia sin fronteras. Disponible en Internet: http://www.concienciasinfronteras.com/PAGINAS/CONCIENCIA/ Dokusho_etica.html. pdf.

${ }^{21}$ Disponible en Internet en http://www3.unesco.org/manifesto2000/pdf/espagnol. 


\section{LuIS IgNACIO NAVARRo GONZÁLEZ}

las víctimas».22 "El caído sufriente no debe ser visto como algo digno de mera conmiseración sino como un sujeto con unas exigencias de dignidad que la solidaridad trata de actualizar removiendo los impedimentos que la obstaculizan. ${ }^{23}$ Ese sujeto caído y sufriente es, ciertamente, el nasciturus.

III.3.C. La ética de la liberación. ${ }^{24}$ Tiene su origen en América Latina y que está defendida por E. Dussel. ${ }^{25}$ "Ante el fracaso del sistema, Dussel afirma la realidad y exterioridad del otro real, histórico y anterior al sistema. Como señala Dussel: «es necesario afirmar la dignidad y la libertad del otro como fundamento de todo».26 Como ya se ha indicado, el otro es, en el caso que estamos estudiando, el nasciturus.

III.3.D. La ética construida desde las víctimas. Basada también en las tesis de Enrique Dussel, esta ética defiende que ante la imposibilidad de que las víctimas no puedan participar simétricamente en los debates acerca de sus derechos, puesto que se trata de seres humanos a los que se les ha cercenado el derecho a la vida antes de nacer, es el estudioso de esta materia el que tiene tres deberes éticos:

1. Reconocer el carácter de víctima del nasciturus.

2. ${ }^{\circ}$ Deconstruir aquellas normas, acciones, instituciones o estructuras históricas que originan la negación material de la víctima; y

3. ${ }^{\circ}$ Transformar o construir aquellas normas, acciones, instituciones o las estructuras necesarias para que los futuros seres humanos no caigan en la condición de víctimas y puedan llegar a vivir en condiciones inherentes a su propia dignidad. Todas las acciones transformativas son las que reciben el nombre -por parte de Dussel- de praxis de liberación». ${ }^{27}$ En el presente estudio esa praxis transformativa se concreta en las propuestas que se hacen de lege ferenda.

${ }^{22}$ DE LA TORRE DÍAZ, Francisco Javier. Op. Cit., p. 144.

${ }^{23}$ Idem, p.145.

${ }^{24} \mathrm{Vid}$., sobre la ética de la liberación: DUSSEL, Enrique: El último Marx (18631882) y la liberación latinoamericana. Un comentario a la tercera y a la cuarta redacción de "El Capital», México, Siglo XXI, 1990. ÁLVAREZ GÓMEZ, Salustiano: La liberación como proyecto ético: un análisis de la obra de Enrique D. Dussel, Madrid, Universidad Complutense, Servicio de publicaciones, 2007. GARCÍA RUIZ, Enrique: Filosofía de la liberación: una aproximación al pensamiento de Enrique Dussel, Driada México, 2003.

${ }^{25}$ DUSSEL, E.: Ética de la liberación, Trotta, Madrid, 1998.

${ }^{26}$ DE LA TORRE DÍAZ, Francisco Javier: Op. Cit., p. 145-146.

${ }^{27}$ DUSSEL, E.: La ética de la liberación. Ante el desafío de Apel, Taylor y Vattimo con respuesta crítica de K. O. Apel. Disponible en Internet: http://168.96.200.17/ar/libros/dussel/taylor/taylor.html. 
III.3.E. La ética personalista. Está basada en varias obras de Kant, entre las que se encuentra la Fundamentación de la metafísica de las costumbres (1785). Afirma Kant que la máxima del sujeto agente es actuar de acuerdo con los principios de universalización y de trato a los otros como fines y no sólo como medios. Un texto que Kant no refirió -pero que nosotros sí podemos referir- al nasciturus, en cuanto que sujeto del derecho a la vida, considerado como un fin en sí mismo y no como mero medio es el siguiente: "El hombre, y en general todo ser racional, existe como fin en sí mismo, no sólo como medio para usos cualquiera de esta o aquella voluntad... ${ }^{28}$ Es evidente que el nasciturus es un ser racional, que tiene naturaleza humana. Y no menos evidente que la voluntad de la madre no puede utilizarlo como un mero medio para fines extraños a su propia dignidad.

III.3.F. La ética comunicativa. Sustentada por J. Habermas, es formulada en virtud del carácter dialógico de la razón humana. «De tal manera que todas las personas son interlocutores válidos y todas están perfectamente legitimadas para exponer sus intereses y deben ser tenidas en cuenta en la decisión final de un acuerdo que satisfaga los intereses de todos».$^{29}$ Esa acción comunicativa se concreta en este estudio en el intento de plantear si puede buscarse un punto de encuentro o equilibrio entre las dos posiciones doctrinales y normativas antagónicas.

\section{III.4. La Teoría de los Derechos Humanos}

Es un estudio realizado desde la Teoría de los Derechos Humanos.

Hay, al menos, un concepto que actúa como presupuesto de todo análisis que se haga dentro de la Teoría de los Derechos Humanos y que constituye, en consecuencia, una condición metodológica. Lo cual implica la necesidad de plantear una pregunta fundamental: ¿Qué debemos entender por derechos humanos? La pregunta es pertinente porque según la respuesta que se dé a la misma dependerá el grado de reconocimiento y protección de los sujetos de derecho implicados en la investigación.

El profesor Narciso Martínez Morán, responde a la cuestión definiendo los derechos humanos como el «conjunto de facultades e instituciones que, en cada momento histórico, permiten realizar las exigen-

\footnotetext{
${ }^{28}$ KANT, E.: Fundamentación de la metafísica de las costumbres, Porrúa, Mexico, 1990, p. 44.

${ }^{29}$ DE LA TORRE DÍAZ, Francisco Javier: Op. Cit., p. 135-136.
} 


\section{LuIS IgNACIO NAVARRo GONZÁLEZ}

cias de la dignidad, la libertad e igualdad humanas, las cuales han de ser reconocidas positivamente por todos los ordenamientos jurídicos, tanto a nivel nacional como internacional». ${ }^{30}$

Minerva Martínez Garza, señala, por su parte, completa la definición añadiendo que "Los derechos humanos expresan el compromiso que debe imperar en todos los ámbitos, a fin de garantizar que todas las personas puedan disfrutar de los bienes y libertades necesarios para una vida digna». ${ }^{31}$ Además, esta autora menciona que «los derechos humanos corresponden a todas las personas y todas las personas tienen igual condición con respecto a esos derechos, aún y cuando se lucha en contra de ancestrales condiciones de desigualdad.» ${ }^{32}$ Aclara lo anterior cuando dice que «la falta de respeto de los derechos humanos de las personas, sea cual sea su origen, condición social o económica, pero muy particularmente, su género, tiene el mismo peso que la falta de respeto hacia cualesquier otro, y no es ni mejor ni peor según el sexo, la raza, el origen étnico, la nacionalidad o cualquier otra distinción. $»^{33}$

Concluye diciendo que «los derechos humanos de una persona se perfeccionan sólo cuando hay mecanismos jurídicos, sociales, económicos, culturales y politicos suficientes para proteger a esa persona de las amenazas contra su integridad y dignidad y para facilitar el ejercicio de las libertades amparadas por esos derechos». ${ }^{34}$

\section{III.5. Metodología de interpretación de las normas jurídicas con relación al aborto inducido: la interpretación sistemática}

Este método de interpretación, aquí adoptado, debe ser entendido en varios sentidos que no son contradictorios entre sí.

\section{III.5.A. La interpretación contextual}

Se adopta, en primer lugar, el significado de interpretación sistemática en el sentido de interpretación contextual, que es la acepción gene-

${ }^{30}$ MARTÍNEZ MORÁN, Narciso, Utopía y realidad de los derechos humanos en el cincuenta aniversario de su Declaración Universal, Universidad Nacional de Educación a Distancia, Madrid, 1999, p. 25.

${ }^{31}$ MARTÍNEZ GARZA Minerva E.: La violencia en contra de las mujeres: una violación al derecho a la igualdad y al principio universal de no discriminación. Especial referencia a México. Tesis de Doctorado en Derecho. Dirigida por Dr. Narciso Martínez Morán. Departamento de Filosofía Jurídica, Facultad de Derecho, Universidad Nacional de Educación a Distancia. Madrid, 2013, p. 39.

\footnotetext{
${ }^{32}$ Idem.

${ }^{33}$ Idem.

${ }^{34} \mathrm{Idem}$.
} 
ralmente seguida en la doctrina iuscivilista. Si aplicamos esta acepción al derecho a la vida del nasciturus y relacionamos el artículo $3 .^{\circ}$ de la Declaración Universal de Derechos Humanos, que reconoce el derecho a la vida de todo ser humano ${ }^{35}$, con otros de la misma Declaración que reconocen los demás derechos, podríamos llegar a la conclusión de que se trata de un derecho humano universal. En efecto, la realización del derecho a la vida, sería la llave que abre la puerta al reconocimiento y garantía de todos los demás derechos, tanto de los derechos civiles y políticos, como económicos, sociales y culturales.

\section{III.5.B. La interpretación integradora.}

Se defiende la interpretación integradora en el sentido de realizar aquella interpretación de los derechos fundamentales que se efectúa conforme al sistema de los derechos humanos, en cuanto que todos ellos constituyen una unidad sistemática. Se parte, en consecuencia, de la consideración sistémica del conjunto de normas de los derechos humanos. Por eso hablamos del sistema de derechos humanos. No hay que olvidar que en la Conferencia Mundial de Derechos Humanos, celebrado en Viena en 1993, se afirmo -a través de la Declaración de Viena- que «Todos los derechos humanos son universales, indivisibles e interdependientes y están relacionados entre sí». ${ }^{36}$ Además, la Constitución mexicana establece, de forma similar, en el párrafo $3 .^{\circ}$ del artículo $10^{\circ}$ que: «Todas las autoridades, en el ámbito de sus competencias, tienen la obligación de promover, respetar, proteger y garantizar los derechos humanos de conformidad con los principios de universalidad, interdependencia, indivisibilidad y progresividad.» ${ }^{37}$ También la Declaración de Viena, de 1993, afirmó de forma inequívoca que: "Los derechos humanos y las libertades fundamentales son patrimonio innato de todos los seres humanos; su promoción y protección es responsabilidad primordial de los gobiernos. 1 $^{38}$

Este criterio hermenéutico viene reconocido también, de forma implícita, en varios artículos del derecho constitucional comparado (como por ejemplo, el artículo 10.2. de la Constitución española de 1978).

III.5.C. La interpretación conforme a los valores jurídicos fundamentales.

${ }^{35}$ ONU: Declaración Universal de Derechos Humanos. En Internet: http://www. acnur.org/t3/fileadmin/scripts/doc.php?file=biblioteca/pdf/0013

${ }^{36}$ ONU: Declaración y Programa de Acción de Viena. Disponible en Internet: http://www.ohchr.org/Documents/Events/OHCHR20/VDPA_booklet_Spanish.pdf.

${ }^{37}$ Constitución Política de los Estados Unidos mexicanos. Disponible en Internet: http://www.ordenjuridico.gob.mx/Constitucion/cn16.pdf.

${ }^{38}$ ONU: Declaración...Cit. 


\section{LuIS IgNACIO NAVARRo GONZÁLEZ}

La interpretación sistemática es una interpretación que respeta los valores fundamentadores de los derechos humanos; especialmente el valor dignidad humana, que es el valor básico, el valor central, el Grundwert. Como señala Maihofer la consideración de la dignidad humana no debe partir del hombre singular, encerrado en su esfera individual, sino de la relación básica (Grundsituation) del ser humano con relación a los demás. Esto significa, en el ámbito que nos ocupa que no puede contemplarse sólo a la mujer como sujeto titular de derecho, uti singuli, contemplando sus derechos sólo desde su individualidad. Habrá, por el contrario, que considerar sus derechos, pero teniendo en cuenta la relación básica, que es la relación que mantiene con otro sujeto de derecho que es el nasciturus, estando ambos vinculados por la relación de embarazo. Junto al valor dignidad, están los demás valores, entre los que destaca como esencial, el valor seguridad jurídica, que exige tanto un inequívoco lenguaje de las normas jurídicas, especialmente de las normas jurídico-penales, como un sistema de garantías que sea adecuado para proteger los bienes de la personalidad, que constituyen el objeto de los derechos. En este caso es el valor vida el especialmente relevante.

III.5.D. Interpretación conforme a la cláusula general antidiscriminatoria.

La interpretación sistemática es también aquella que respeta la cláusula general antidiscriminatoria, que forma parte del contenido esencial del derecho a la igualdad y que está recogida tanto en las normas de derecho internacional universal y regional, como en el derecho comparado y en el propio sistema jurídico mexicano. La cláusula está reconocida también en el artículo $1 .^{\circ}$ de la Constitución mexicana ${ }^{39}$ :

"Queda prohibida toda discriminación motivada por origen étnico o nacional, el género, la edad, las discapacidades, la condición social, las condiciones de salud, la religión, las opiniones, las preferencias sexuales, el estado civil o cualquier otra que atente contra la dignidad humana y tenga por objeto anular o menoscabar los derechos y libertades de las personas...».

III.5.E. Interpretación de la Constitución y «desde» la Constitución. La interpretación sistemática implica asumir el significado de las normas jurídicas mexicanas a partir de la distinción que hace, entre otros autores, el profesor Pérez Luño entre «interpretación de la Constitución e Interpretación «desde» la Constitución,» que, a su vez, deriva y es consecuencia directa del principio de jerarquía normativa. ${ }^{40}$ Este

${ }^{39}$ Constitución de los Estados Unidos mexicanos. Disponible en Internet:

http://www.ordenjuridico.gob.mx/Constitucion/cn16.pdf.

${ }^{40}$ PÉREZ LUÑO, A. E.: Derechos Humanos, Estado de Derecho y Constitución, 8. ${ }^{a}$ edición, Tecnos, Madrid, 2003, pp. 279 y ss. 
ESTUDIO CRÍTICO DE UN NUEVO DILEMA EN EL SISTEMA JURÍDICO MEXICANO...

criterio hermenéutico está apoyado además, normativamente, por el artículo $1 .^{\circ}$ de la Constitución mexicana que establece que «las normas relativas a los derechos humanos se interpretarán de conformidad con esta Constitución... » ${ }^{41}$

III.5.F. Interpretación conforme al principio de legalidad constitucional.

La interpretación sistemática es aquella que reconoce el principio de legalidad constitucional que viene reconocido en el artículo 1 de la Constitución mexicana: «Las normas relativas a los derechos humanos se interpretarán de conformidad con esta Constitución y con los tratados internacionales de la materia favoreciendo en todo tiempo a las personas la protección más amplia». ${ }^{42}$

III.5.G. Interpretación conforme al principio de unidad constitucional, que significa que el conjunto de normas que componen la Constitución forman una totalidad sistemática. Lo cual impide que el intérprete pueda considerar las normas constitucionales como entes individuales aislados. ${ }^{43}$

III.5.H. Interpretación conforme al reconocimiento del principio de supremacía constitucional ${ }^{44}$, que se desprende de los artículos 15 , 40, 41, primer párrafo, 128 y 133 de la Constitución Federal.

III.5.I. Interpretación realizada conforme al principio de no contradicción. Del principio de unidad constitucional deriva otro sumamente importante: el principio que afirma que la interpretación en ningún caso debe quebrar el principio lógico de no contradicción. Esta interpretación implica que las normas jurídicas de un determinado sistema jurídico, en este caso, el sistema jurídico mexicano, no pueden ser contradictorias entre sí. Lo contrario rompería los principios de coherencia y sistematicidad característicos en todo Estado que se estructure conforme al modelo de Estado de Derecho, como es el caso de México. En el caso que estamos analizando en el presente trabajo la aplicación de este principio significa que no puede la legislación mexicana afirmar, reconocer y proteger el derecho a la vida y la

${ }^{41}$ Constitución Política de los Estados Unidos mexicanos. Disponible en Internet: http://www.ordenjuridico.gob.mx/Constitucion/cn16.pdf.

${ }^{42}$ Constitución Política de los Estados Unidos mexicanos. Disponible en Internet: http://www.ordenjuridico.gob.mx/Constitucion/cn16.pdf.

${ }^{43}$ PÉREZ LUÑO, A. E.: Derechos Humanos, Estado de Derecho y Constitución, 8. ${ }^{a}$ edición, Tecnos, Madrid, 2003, pp. 276 y ss.

${ }^{44}$ BURGOA O. Ignacio: Garantías Individuales. Porrúa, México, 2010, p. 363.

(C) UNED. Revista de Derecho UNED, núm. 16, 2015 


\section{LuIS IgNACIO NAVARRo GONZÁLEZ}

protección del bien vida, y al mismo tiempo, sustentar la legalidad y legitimidad del aborto inducido como un derecho fundamental dentro de un determinado plazo del embarazo.

III.5.J. Interpretación realizada conforme al principio de prohibición de interpretación restrictiva de derechos fundamentales. Supone este principio que toda interpretación sobre el contenido de un determinado derecho fundamental debe ser siempre considerado en su significación más extensa y nunca en su significación más restringida. Este criterio, que tiene su fundamento en la naturaleza expansiva de los derechos humanos, ${ }^{45}$ alcanza a tener reconocimiento en el Derecho constitucional comparado ${ }^{46}$ y en el propio sistema jurídico mexicano.

III.5.K. Interpretación realizada conforme al reconocimiento y garantía del principio favor libertatis, lo que implica concebir el proceso hermenéutico de los derechos fundamentales, como una labor tendente a maximizar y optimizar la fuerza expansiva y la eficacia de los derechos fundamentales en su conjunto. ${ }^{47}$

III.5.L. Interpretación realizada en el sentido de reconocer y garantizar el principio in dubio pro libertate. Este principio implica que, en caso de duda, habrá que estar a favor siempre del sentido más favorable para la existencia y garantía de un derecho fundamental. Principio explícitamente reconocido por la opinión dominante en la doctrina ${ }^{48}$ e implícitamente por varias normas internacionales de derechos humanos, como son: El artículo 30 de la Declaración Universal de Derechos Humanos y la Declaración de los Derechos y Libertades Fundamentales de 16 de Mayo de 1989, entre otros muchos textos de derechos humanos.

${ }^{45}$ LIMA TORRADO, Jesús y ROVETTA KLYVER, F.: Cursos sistemático de derechos humanos, op. Cit. Disponible en Internet: http://www.iepala.es/curso_ddhh/ ddhh_c.htm.

${ }^{46}$ La Constitución brasileña de 1988 afirma que las normas definidoras de los derechos fundamentales son de aplicación inmediata (artículo 5§1. ${ }^{\circ}$ de la Constitución de 1988) en virtud del principio de máxima efetividade, también denominado princípio da eficiência.

${ }^{47}$ PÉREZ LUÑO, A. E.: Derechos Humanos, Estado de Derecho y Constitución, 8. ${ }^{a}$ edición, Tecnos, Madrid, 2003, pp. 315-316.

${ }^{48}$ PÉREZ LUÑO, A. E.: Derechos Humanos, Estado de Derecho y Constitución, 8. ${ }^{\mathrm{a}}$ edición, Tecnos, Madrid, 2003, pp. 315-316. 


\section{EL CARÁCTER DILEMÁTICO DEL ABORTO INDUCIDO EN EL ÁMBITO DEL DERECHO}

\section{IV.1. El concepto de dilema}

Por dilema, en general, entiendo el problema derivado de tener que elegir entre dos alternativas mutuamente excluyentes, ya sea en el ámbito semántico, ya sea en el ámbito lógico-conceptual, ya sea en el ámbito epistemológico, ya sea en el ámbito moral o ya sea, finalmente, en el ámbito jurídico normativo. ${ }^{49}$

\section{IV.2. Los cinco tipos de dilemas en la legislación mexicana}

En el vigente Código Penal del Distrito Federal de 2007, nos encontramos que en el lenguaje normativo con relación al aborto inducido se produce una concentración de esas cinco diversas manifestaciones de dilemas:

\section{IV.2.A. El dilema semántico.}

En primer lugar se verifica la existencia de un dilema semántico en la medida en que se produce un cambio sustantivo en el lenguaje.

Se produce el dilema porque aborto e interrupción voluntaria del embarazo no son términos sinónimos. El significado de aborto implica la idea central de la destrucción del nasciturus. En el significado de la expresión interrupción voluntaria del embarazo, que adolece de las "enfermedades» del eufemismo ${ }^{50}$, de la antilengua y de la neolengua ${ }^{51}$, ese significado central queda suprimido. La exclusión de ese significado prepara y encubre la exclusión social efectiva. Por eso se puede afirmar que este dilema prepara o determina los otros niveles.

La expresión interrupción voluntaria del embarazo es un eufemismo, porque en ella concurren los cuatro fines que atribuye Bernardino M. Hernando a los eufemismos: $1 .^{\circ}$ Disfrazar lo feo de lo bonito;

${ }^{49}$ BUNGE, Mario: Voz dilema en Diccionario de Filosofía, Siglo XXI Editores, 3. ${ }^{\text {a }}$ Edición, 2005, p. 52

${ }^{50}$ LÓPEZ MORENO, Ángeles: Reflexiones jurídicas del Proyecto de Ley de Salud sexual y reproductiva y de la interrupción voluntaria del embarazo, Murcia, 2009, p. 13.

${ }^{51}$ El significado de las tres «enfermedades» descritas y su repercusión en la regulación actual del aborto inducido está siendo tratado y desarrollado en la tesis doctoral que será presentada en la UNED en fechas próximas. 


\section{LuIS IgNACIO NAVARRo GONZÁLEZ}

2. ${ }^{\circ}$ Disfrazar lo fácil de complicado; $3 .^{\circ}$ Disfrazar la vacuidad de palabrería y $4 .^{\circ}$ Disfrazar lo concreto de vaguedades. ${ }^{52}$

Esa expresión participa de la antilengua porque en ella «los significados son continuamente eludidos, relegados, en el fondo a una perspectiva de vocablos que nada quieren decir, en sí mismos o quieren decir algo vago e inaprensible. ${ }^{53}$

A través de la neolengua, se pretende encubrir, ideológicamente, la realidad dramática consustancial al aborto. Por eso, se habla de interrumpir y no de finalizar el embarazo.

Es importante señalar que tanto la Asamblea Legislativa del Distrito Federal, como los que promovieron la controversia constitucional, así como los Ministros de la Suprema Corte de Justicia de la Nación, emplearon el término interrupción voluntaria del embarazo, cuando lo correcto habría sido denominarlo -tal y como sucede en muchos otros países- finalización del embarazo. Así sucede en diversos países europeos, como Bélgica (reforma legal de 3 de Abril de 1990), Finlandia (Ley 328 de 6 de Abril de 2001), Luxemburgo (Ley de 15 de Noviembre de 1978), Italia (Ley de 22 de Mayo de 1978), Países Bajos (Ley de 1 de Mayo de 1981), Dinamarca (Ley de 13 de Junio de 1973, reformada en el año 2003), Estonia (Ley de 2004), Reino Unido (Ley de Octubre de 1967, reformada en Abril de 1990), Suecia(Ley de 1974, reformada en 1995) y Polonia (Ley de 7 de Enero de 1993). En todos ellos el término utilizado es «terminación» y no «interrupción». ${ }^{54}$

\section{IV.2. B. El dilema lógico.}

Se constata la existencia de un dilema lógico en la medida en la reforma del Código Penal de Distrito Federal introduce una nueva definición de aborto.

Antes de la reforma de 2007, por la que se introduce una modificación legal en el Código Penal del Distrito Federal, se utilizaba el término «aborto» (artículo 144): "Aborto es la muerte del producto de la concepción en cualquier momento del embarazo».

${ }^{52}$ Citado por NÚÑEZ CABEZAS, Emilio Alejandro: Aproximación al léxico del lenguaje político español. Tesis Doctoral dirigida por el profesor Dr. D. Antonio M. Garrido Moraga, Departamento de Filología Española III, Teoría de la Literatura y Periodismo, Universidad de Málaga, 2000, p. 47.

${ }^{53}$ CALVINO, Italo: L'antilingua en Saggi (1945-1985). Edición de Mario Barenghi, Mondadori, 1985También en Internet: http://new.lettere.unina2.it/Didattica1/Dispense/Proietti/LingIt2011-12-Dispense/28-3-2012/CalvinoPasolini.pdf.

${ }^{54}$ LÓPEZ MORENO, Ángeles: Reflexiones jurídicas del Proyecto de Ley de Salud sexual y reproductiva y de la interrupción voluntaria del embarazo, Murcia, 2009, p. 13. 
A partir de la reforma se habla de «interrupción voluntaria del embarazo». Con lo cual la antigua definición queda partida en dos significados radicalmente antagónicos: la interrupción voluntaria del embarazo, comprendida en el periodo de tiempo existente entre la anidación y la duodécima semana de gestación y el aborto, definido a partir de este último periodo de tiempo. En efecto dice el actual artículo 144: Aborto es la interrupción del embarazo después de la décimo segunda semana de gestación. Para los efectos de este código el embarazo es la parte del proceso de la reproducción humana que comienza con la implantación del embrión en el endometrio.»

La contradicción existe no sólo con relación a la antigua redacción del Código Penal del Distrito Federal, sino también con relación al actual Código Penal Federal. ${ }^{55}$ En efecto, el Capítulo VI del Título Decimonoveno, referente al aborto, dispone en el Artículo 329, que:« Aborto es la muerte del producto de la concepción en cualquier momento de la preñez»

Esta definición coincide plenamente con la antigua redacción, ya citada, del Código Penal del Distrito Federal pero entra en colisión radical directa con el contenido del actual artículo 144 del mismo código. Teniendo en cuenta que la norma federal es superior a la del Distrito Federal, parece obvio que incurre en inconstitucionalidad, en virtud de no respetar la fracción XXI, inciso c) del artículo 73 de la Constitución Política de los estados Unidos Mexicanos.

\section{IV.2.C. El dilema epistemológico.}

Es observable la existencia de un tercer nivel de planeamiento contradictorio. Es el constituido por el dilema epistemológico.

A partir de la existencia de un reconocimiento normativo de la interrupción voluntaria del embarazo con lo excluido de la sanción penal y como parte de un ámbito de licitud jurídica, se están formulando durante los últimos años, planteamientos que pretenden subsumir o integrar la mal llamada interrupción voluntaria del embarazo dentro de los derechos a la salud sexual y reproductiva y éstos, a su vez, en los derechos civiles y políticos, de un lado, y económicos sociales y culturales, por otro. Lo cual ha llevado a un sector de la doctrina a afirmar la existencia de un derecho al aborto o a la interrupción voluntaria del

\footnotetext{
${ }^{55}$ Código Penal Federal, publicado en el Diario Oficial de la Federación el 14 de agosto de 1931. Disponible en Internet: http://www.diputados.gob.mx/LeyesBiblio/ pdf/9_140714.pdf.
} 


\section{LuIS IgNACIO NAVARRo GONZÁLEZ}

embarazo como un derecho humano. ${ }^{56}$ Defender la existencia de ese supuesto derecho es sencillamente un disparate, porque no puede afirmarse la existencia de un derecho si ello supone la supresión de otro. No hay que olvidar que los derechos humanos están coordinados entre sí y que forman, en consecuencia, un sistema.

\section{IV.2.D. El dilema moral.}

El dilema moral viene constituido por la necesidad de optar entre una ética personalista, basada en la idea central de la esencial igualdad y dignidad de todos los seres humanos, incluyendo, en consecuencia, al nasciturus; o por el contrario una ética transpersonalista, en el que el otro, es decir, el nasciturus, queda excluido.

\section{IV.2.E. El dilema legal}

El dilema legal está determinado por dos factores.

En primer lugar por el contenido de la materia regulada. Los dilemas anteriormente expuestos se manifiestan y se reproducen en las normas jurídicas en el momento en el que el legislador tiene que abordar la materia y regularla. El legislador se ve en la necesidad de elegir, como más jurídicamente correcta, una de las dos propuestas sociales que son radicalmente antagónicas. De un lado, están los movimientos sociales que defienden que el bien jurídico fundamental viene constituido por la libertad de autodeterminación de la mujer, que puede tomar en el ejercicio de su libertad individual, la decisión de abortar sin que de esa acción derive un reproche social de carácter penal. Para esta propuesta el nasciturus no es sujeto de derecho. Se está, por tanto, en una situación de grave confrontación con la protección de la vida prenatal. Para las organizaciones y pensadores que defienden la posición contraria al aborto el bien jurídico a proteger es, fundamentalmente, el bien vida, en el que está como sujeto titular el nasciturus, bien que, en modo alguno puede ser soslayado porque significa la negación radical de todos sus derechos, incluido el derecho a nacer. ${ }^{57}$ Esta segunda opción no implica la negación a la mujer de los derechos a la salud sexual y reproductiva, sino, antes bien, la

${ }^{56}$ ALFARACHE LORENZO, Angela: La construcción del aborto como un derecho humano de las mujeres en Castañeda Salgado, Martha Patricia (Coord.): Interrupción voluntaria del embarazo. Reflexiones teóricas, filosóficas y políticas, Centro de Investigaciones Interdisciplinarias en Ciencias y Humanidades, UNAM, México, 1. ${ }^{\circ}$ Edición, 2003, pp. 131 y ss.

${ }^{57}$ Opinión del Comité de Bioética ...Op. Cit, p. 6 en Internet: http://www.comitedebioetica.es/documentacion/docs/es/consenso_interrupcion_embarazo_comite_bioetica_oct_2009.pdf. 
necesaria armonización y equilibrio entre los derechos fundamentales de los dos sujetos titulares de derechos: el nasciturus y la madre.

El segundo factor es la forma de regulación llevada a cabo por la nueva reforma del Código Penal del Distrito Federal, que incide en una serie de contradicciones que afectan directamente: a los valores jurídicos, a los principios y a los mismos derechos, todos ellos de rango fundamental.

IV.2.E: a. Contradicción con los valores jurídicos fundamentales.

A diferencia de lo que ocurre en la Constitución Española de 1978, no existe en la Constitución Federal mexicana un reconocimiento explícito del valor central inspirador de los derechos fundamentales: el valor dignidad. No obstante existe un reconocimiento del mismo a través de la fundamentación que hace el artículo $1 .^{\circ}$ de la Constitución Federal -junto con el valor igualdad- de la prohibición de discriminación: "Queda prohibida toda discriminación motivada por origen étnico o nacional, el género, las condiciones de salud, la religión, las opiniones, las preferencias sexuales, el estado civil o cualquier otra que atente contra la dignidad humana y tenga por objeto anular o menoscabar los derechos y libertades de las personas.»

IV.2.E.: b. Contradicción con los principios jurídicos fundamentales.

Entre los principios jurídicos conculcados por la actual legislación mexicana están, además de los ya señalados en el apartado dedicado a la metodología, el principio de jerarquía normativa y el principio de supremacía constitucional.

El principio de jerarquía normativa, viene establecido en el artículo 133 de la Constitución Federal ${ }^{58}$ que implica que las normas inferiores no pueden contradecir ni vulnerar aquellas que sean de rango superior.

${ }^{58}$ Este principio ya había sido previsto por una serie de normas anteriores a la Constitución Federal. Es el caso del artículo 237 de la Constitución de Apatzingán (1814); del Reglamento Provisional Político del Imperio Mexicano (1822); del artículo 27 del Acta Constitutiva y de Reformas (1824); del artículo 161, fracción III, de la Constitución Federal de 1824, y del artículo 126 de la Constitución de 1857. En este último precepto era casi idéntico al señalado en el Artículo seis, párrafo segundo de la constitución de los Estados Unidos de América. Más tarde, en el Congreso Constituyente de 1916-1917, el principio se incluyó en el artículo 133, aprobado por votación unánime de 154 diputados. 


\section{Luis IgNaCio NaVARRo GoNZÁLEZ}

El principio de supremacía constitucional ${ }^{59}$ se desprende de los artículos 15, 40, 41, primer párrafo, 128 y 133 de la Constitución Federal. Especialmente relevante es el contenido del artículo 133:

"Esta constitución, las leyes del Congreso de la Unión que emanen de ella y todos los Tratados que estén de acuerdo con la misma, celebrados y que se celebren por el Presidente de la República, con aprobación del Senado, serán la Ley Suprema de toda la Unión. Los jueces de cada Estado se arreglarán a dicha constitución, leyes y tratados, a pesar de las disposiciones en contrario que pueda haber en las constituciones o leyes de los Estados. ${ }^{60}$

En virtud del artículo 133 de la Constitución mexicana ${ }^{61}$ la jerarquía del orden jurídico es la siguiente: $1 .^{\circ}$ La Constitución; $2 .^{\circ}$ Los tratados internacionales y las leyes federales; $3 .^{\circ}$ Las leyes ordinarias; $4 .^{\circ}$ Los decretos; $5 .^{\circ}$ Los reglamentos y $6 .^{\circ}$ Las normas jurídicas individualizadas.

Los tribunales del Poder Judicial de la Federación han resuelto que del principio de supremacía constitucional se desprenden diversas implicaciones:

En primer lugar, al ser la constitución la Ley Suprema de la nación, su contenido no puede desvirtuarse por ningún otro ordenamiento legal, pues se sobrepone a las leyes comunes federales y locales; ${ }^{62}$ es decir, tales ordenamientos guardan una subordinación natural respecto de la Constitución. ${ }^{63}$

En segundo lugar, los Estados deben sujetarse a los mandatos de la Constitución, considerada constitutiva del sistema federal, aun cuando sean libres y soberanos en cuanto a su régimen interior; por tanto, siempre que una ley local contraríe los preceptos constitucionales, éstos deben prevalecer, incluso en el supuesto de que la legislación expedida por la Legislatura local se adecue a su propia constitución y emane de autoridad competente, ${ }^{64}$ ya que dichos Estados deben permanecer en unión con la Federación, según los principios de la propia Ley Fundamental.

En tercer lugar, toda institución o dependencia, así como todo individuo, deben someterse a las disposiciones constitucionales, respe-

${ }^{59}$ BURGOA O. Ignacio, ob. cit., p. 363

${ }^{60}$ Ibídem.

${ }^{61}$ Ibídem.

${ }^{62}$ Semanario Judicial de la Federación, Sexta Época, vol. XLIV, Primera Parte, p. 28.

${ }^{63}$ Semanario Judicial de la Federación, Octava Época, t. I, Segunda Parte, enero a junio de 1998, p. 394.

${ }^{64}$ Semanario Judicial de la Federación, Séptima Época, vol. 40, Primera Parte, p. 45. 
ESTUDIO CRÍTICO DE UN NUEVO DILEMA EN EL SISTEMA JURÍDICO MEXICANO...

tando sus garantías y postulados, sin que ninguna persona -física o moral, pública o privada- pueda desconocerlas. ${ }^{65}$

En cuarto lugar, todas las normas secundarias, en cuanto no estén en franca contradicción con la constitución, deben interpretarse de manera tal que no se le opongan; ${ }^{66}$ es decir, deben rechazarse categóricamente interpretaciones jurídicas opuestas al texto y sentido de la Ley Suprema. ${ }^{67}$

Y en quinto lugar, en virtud de su jerarquía, la constitución únicamente puede modificarse o adicionarse con base en los lineamientos que para tal efecto se indican en ella, ${ }^{68} \mathrm{y}$ por conducto de un órgano especialmente calificado. ${ }^{69}$

IV.2.E: c. Contradicción con los derechos fundamentales

La actual regulación del aborto inducido entra en contradicción radical con el derecho a la vida. Es un derecho que no está explícitamente reconocido en la Constitución mexicana pero si de una manera implícita. Esa circunstancia no puede servir de excusa para defender la existencia de un pretendido derecho al aborto a costa de sacrificar otro derecho fundamental.

\section{CONCLUSIONES}

1. La regulación del aborto inducido es de tal complejidad que las preguntas fundamentales que suscita son cuestiones abiertas; de tal manera que se puede afirmar que no tienen respuestas que sean universalmente válidas e incontestables.

2. Es, además, una realidad, dramática, que afecta hoy pero también en el pasado a prácticamente todas las sociedades y que ante ella, por su propia naturaleza, el Derecho no puede ni debe inhibirse.

3. ${ }^{a}$ La compleja problemática del aborto inducido se ha convertido en uno de los temas nacionales de muchos países, tales como Alemania, Francia, Italia, España o México. Se ha llegado a afirmar in-

${ }^{65}$ Gaceta del Semanario Judicial de la Federación, Octava Época, No. 86, febrero de 1995, p. 19.

${ }^{66}$ Semanario Judicial de la Federación, Octava Época, t. VIII, febrero de 1991, p. 53.

${ }^{67}$ Semanario Judicial de la Federación y su Gaceta, Novena Época, t. XII, octubre de 2000, p. 30.

${ }^{68}$ Artículo 135 de la Constitución Política Federal. [En línea], consultada el 02 de enero del 2014 en: http://www.diputados.gob.mx/LeyesBiblio/index.htm

${ }^{69}$ Semanario Judicial de la Federación, Séptima Época, vol. 39, Primera Parte, p. 22.

(C) UNED. Revista de Derecho UNED, núm. 16, 2015 


\section{LuIS IgNACIO NAVARRo GONZÁLEZ}

cluso que se trata de una cuestión esencial para todos y cada uno de los habitantes de México.

4. ${ }^{\circ}$ Los criterios metodológicos utilizados se fundamentan en la Teoría Crítica de los derechos Humanos, en la interdisciplinariedad y en la utilización de la interpretación sistemática.

5. A partir de una determinada definición de dilema se constata, en el sistema jurídico mexicano, la existencia de cinco niveles dilemáticos.

6. ${ }^{\circ}$ La existencia de dilemas es consecuencia y efecto de las radicales contradicciones en que incurre, en el sistema jurídico Mexicano, la reforma de Código Penal del Distrito Federal, de 2007.

7. Se verifica la existencia de un dilema semántico en la medida en que se produce un cambio sustantivo en el significado de los términos aborto e interrupción voluntaria del embarazo. El aborto implica el significado central de la destrucción y muerte del nasciturus. Ese significado desaparece en la otra expresión, cuyo significado central no incluye al nasciturus y sí, en cambio, sólo la libertad de autodeterminación de la mujer.

8. ${ }^{a}$ El dilema semántico es consecuencia de la existencia de tres «enfermedades» que no sólo constituye un empobrecimiento del lenguaje, sino que además, determina los otros cuatro niveles dilemáticos. Esas «enfermedades» son el eufemismo, la antilengua y la neolengua.

9. Se constata la existencia de un segundo dilema, de naturaleza lógica, en la medida en que la reforma de Código Penal del Distrito Federal, introduce una nueva definición de aborto que se contradice radicalmente con la definición de aborto en el Código Penal Federal, y los códigos penales de los diversos estados.

$10 .^{\circ}$ Es observable la existencia de un tercer nivel de planeamiento contradictorio. Es el constituido por el dilema epistemológico, cuyo sujeto enunciador es la ciencia jurídica. Este dilema permite incluso justificar y enmascarar la pretendida existencia de un derecho autónomo, excluyente, que, en última instancia, recibiría el nombre de derecho al aborto como derecho humano.

11. ${ }^{\circ}$ El dilema moral, que constituye el cuarto nivel, viene constituido por la necesidad de optar entre una ética personalista, basada en la idea central de la esencial igualdad y dignidad de todos los seres humanos, incluyendo, en consecuencia, al nasciturus o; por el contrario, por una ética transpersonalista, que supondría la cosificación del 
aún no nacido, permitiendo, en consecuencia, la defensa y justificación ética de conversión del nasciturus de persona en no- persona y de sujeto en objeto.

12. ${ }^{\circ}$ El dilema legal constituye el quinto nivel dilemático. Está determinado por dos factores: la materia regulada y la política legislativa seguida en la reforma del Código Penal del Distrito Federal, más exactamente en el ámbito competencial, puesto que no están adecuadamente delineadas las competencias legislativas con relación al aborto inducido entre la esfera federal y la estatal. Lo que da origen a una duplicidad de leyes en ambas esferas jurídicas que regulan idénticas conductas, como es el delito de aborto, pero con soluciones antagónicas.

13. ${ }^{\circ}$ La mal llamada interrupción voluntaria del embarazo no es sólo el derecho de la mujer al ejercicio de su libertad personal, sino también el final o la muerte de una vida humana.

14..$^{\circ}$ Aunque el reconocimiento del derecho a la vida en el Derecho Constitucional mexicano no es explícito, esto no debe servir de criterio argumentativo para justificar, como hacen las autoridades mexicanas la incorporación de las tesis proabortistas en el Código Penal del Distrito Federal.

15. ${ }^{\circ}$ La protección del derecho a la vida del nasciturus deriva tanto de la Constitución Política de los Estados Unidos Mexicanos, como de los tratados internacionales y las leyes federales, de los Códigos Penal Federal y Penal para el Distrito Federal, y de los Códigos Civil Federal y Civil para el Distrito Federal Civiles y leyes de los estados.

16. ${ }^{\circ}$ La situación planteada en el punto anterior implica, entre otras cosas, la impunidad de delitos de esta naturaleza realizados en otros estados mexicanos. Situación se produce mediante el simple hecho de que las mujeres, deseosas de abortar sólo se trasladen al Distrito federal para que su conducta sea plenamente lícita.

17. ${ }^{\circ}$ Pero, ¿acaso el derecho a la libertad de autodeterminación de la mujer es un derecho absoluto e ilimitado? ¿el ejercicio del principio de autonomía le otorga el derecho a decidir con respecto a la continuidad o no de un embarazo?

\section{BIBLIOGRAFÍA}

ALFARACHE LORENZO, Angela: La construcción del aborto como un derecho humano de las mujeres en Castañeda Salgado, Martha Pa-

(C) UNED. Revista de Derecho UNED, núm. 16, 2015 


\section{Luis IgNaCio NaVARRo GoNZÁLEZ}

tricia (Coord): Interrupción voluntaria del embarazo. Reflexiones teóricas, filosóficas y políticas, Centro de Investigaciones Interdisciplinarias en Ciencias y Humanidades, UNAM, México, $1 .^{\circ}$ Edición, 2003.

BERMÚDEZ VALDIVIA, Violeta: La regulación jurídica del aborto en América Latina y el Caribe, CLADEM, Lima, 1998.

BUNGE, Mario: Voz dilema en Diccionario de Filosofía, Siglo XXI Editores, 3. ${ }^{\text {a }}$ Edición, 2005.

BURGOA ORIHUELA, Ignacio, Garantías Individuales. Porrúa, México, 2010.

CARPIZO, Jorge, VALADÉS, Diego: Derechos Humanos. Aborto y eutanasia. UNAM, Instituto de Investigaciones Jurídicas, México, 2008.

Código Penal Federal, publicado en el Diario Oficial de la Federación el 14 de agosto de 1931. Disponible en Internet: http://www.diputados.gob.mx/LeyesBiblio/pdf/9_140714.pdf.

COELHO, Luiz Fernando: Teoría Crítica del Derecho, 4. ${ }^{a}$ Edición, Juruá, Curitiba, 2012.

COMITÉ DE BIOÉTICA DE ESPAÑA: Opinión del Comité de Bioética de España a propósito del Proyecto de Ley Orgánica de Salud Sexual y Reproductiva y de la Interrupción voluntaria del embarazo, 7 de Octubre de 2009, p. 4 en Internet: http://www.comitedebioetica.es/ documentacion/docs/es/consenso_interrupcion_embarazo_comite_bioetica_oct_2009.pdf.

CONSEJO FISCAL: Informe aprobado por el Consejo Fiscal sobre el Anteproyecto de Ley de Salud Sexual y reproductiva y de la interrupción voluntaria del embarazo en Internet:

http://www.abortoinformacionmedica.es/2009/06/28/informe-delconsejo-fiscal-sobre-el-anteproyecto/

Constitución de los Estados Unidos mexicanos. Disponible en Internet: http://www.ordenjuridico.gob.mx/Constitucion/cn16.pdf.

DE LA TORRE DÍAZ, Francisco Javier:. ¿Qué metaéticas fundamentan o podrían fundamentar los derechos humanos? en Milans de Bosch Portolés, Ivan, Madrazo Rivas, Enrique, De la Torre Díaz, Francisco Javier (Coordinadores): La universidad como agente de cooperación al desarrollo, Dykinson, Madrid, 2002. 
ESTUDIO CRÍTICO DE UN NUEVO DILEMA EN EL SISTEMA JURÍDICO MEXICANO...

Decreto por el que se reforma el Código Penal para el Distrito Federal y se Adiciona la Ley de Salud para el Distrito Federal, Gaceta Oficial del Distrito Federal, N. ${ }^{\circ}$ 70, Mexico, Distrito Federal, 26 de Abril de 2007.

DUSSEL, E.: La ética de la liberación. Ante el desafío de Apel, Taylor y Vattimo con respuesta crítica de $K$. O. Apel. Disponible en Internet: http://168.96.200.17/ar/libros/dussel/taylor/taylor.html.

DWORKIN, R.: El dominio de la vida: una discusión acerca del aborto, la eutanasia y la libertad individual, Ariel, Madrid, 1994.

GARCÍA PASCUAL, C: Cuestiones de vida o muerte: los dilemas éticos del aborto en Derechos y Libertades, N. ${ }^{\circ}$ 16, Época II, Enero de 2007.

KANT, E.: Fundamentación de la metafísica de las costumbres, Porrúa, México, 1990

LIMA TORRADO, J.: Globalización y Derechos Humanos en Anuario de Filosofía del Derecho, Madrid, Nueva época, Tomo XVII, 2000.

LÓPEZ MORENO, Ángeles: Reflexiones jurídicas del Proyecto de Ley de Salud sexual y reproductiva y de la interrupción voluntaria del embarazo, Murcia, 2009

MARTÍNEZ GARZA Minerva E.: La violencia en contra de las mujeres: una violación al derecho a la igualdad y al principio universal de no discriminación. Especial referencia a México. Tesis de Doctorado en Derecho. Dirigida por Dr. Narciso Martínez Morán. Departamento de Filosofía Jurídica, Facultad de Derecho, Universidad Nacional de Educación a Distancia. Madrid, 2013.

MARTÍNEZ MORÁN, Narciso, Utopía y realidad de los derechos humanos en el cincuenta aniversario de su Declaración Universal, Universidad Nacional de Educación a Distancia, Madrid, 1999.

MASIÁ CLAVEL, Juan: Bioética y Antropología, 2. a Edición, Universidad Pontificia de Comillas, Madrid, 1998. Campos Salas, Jeanette: El dilema del aborto, Uruk Editores, 2008.

ONU: Declaración Universal de Derechos Humanos. Disponible en Internet: http://www.acnur.org/t3/fileadmin/scripts/doc. php?file=biblioteca/pdf/0013.

ONU: Declaración y Programa de Acción de Viena. Disponible en Internet: http://www.ohchr.org/Documents/Events/OHCHR20/VDPA_ booklet_Spanish.pdf. 


\section{Luis IgNaCio NaVARRo GoNZÁLEZ}

OST, François: Jalons pour une Théorie critique du Droit, Publications des Facultes, Universitaires, St. Louis, Bruselas, 2002.

PÉREZ LUÑO, A. E.: Derechos Humanos, Estado de Derecho y Constitución, 8. ${ }^{\text {a }}$ edición, Tecnos, Madrid, 2003.

ROSTAGNOL, Susana: Lugares y sentidos del aborto voluntario: un diálogo con la bioética en Perspectivas bioéticas, Ediciones del Signo, Año 2011, N. ${ }^{\circ} 21$.

Suprema Corte de Justicia de la Nación. Semanario Judicial de la Federación, Sexta Época, vol. XLIV, Primera Parte.

Suprema Corte de Justicia de la Nación. Semanario Judicial de la Federación, Octava Época, t. I, Segunda Parte, enero a junio de 1998.

Suprema Corte de Justicia de la Nación. Semanario Judicial de la Federación, Séptima Época, vol. 40, Primera Parte.

TAMAYO Y TAMAYO, Mario: Diccionario de la investigación científica, 2. ${ }^{a}$ edición, Limusa, México, 2004.

VILLALBA, Dokushô: La ética, corazón de una nueva civilización en Conciencia sin fronteras. Disponible en Internet:

http://www.concienciasinfronteras.com/PAGINAS/CONCIENCIA/ Dokusho_etica.html.

WOLKNER, Antonio Carlos: Introducción al pensamiento jurídico crítico,1. a Edición, ILSA, Bogotá, 2003. 